\title{
Relationship Between Ossicular Chain Erosion and Facial Canal Dehiscence in Chronic Otitis Media Squamous
}

\author{
Bijaya Kharel', Ashok Shreepaili², Prashant Tripathi', Yogesh Neupane', Urmila Gurung ${ }^{1}$, Rabindra \\ B Pradhananga', Pabina Rayamajhi', Hari Bhattarai ${ }^{1}$ \\ ${ }^{1}$ Department of ENT- Head and Neck Surgery, Maharajgunj Medical Campus, Ganesh Man Singh Memorial \\ Academy of ENT - Head \& Neck Studies, Tribhuvan University Teaching Hospital, Institute of Medicine, Kathmandu, \\ Nepal, ${ }^{2}$ Department of ENT \& HNS, Seti Provincial Hospital, Dhangadhi, Nepal
}

\section{Corresponding author:}

\section{Rabindra B Pradhananga, MBBS, MS}

Department of ENT- Head and Neck Surgery, Maharajgunj Medical Campus, Ganesh Man Singh Memorial Academy of ENT - Head \& Neck Studies, Tribhuvan University Teaching Hospital, Institute of Medicine, Kathmandu, Nepal

Email: rabindra9034@gmail.com

Submitted : May 2, 2020

Accepted : July 18,2020

\begin{abstract}
\section{Introduction}

Chronic otitis media squamous is a gradually expanding destructive lesion and leads to complications by eroding the adjacent structures. Facial canal and ossicles are in close proximity in the middle ear space and they share the same pathogenesis of the bony erosion. Ossicular chain erosion found intraoperatively due to cholesteatoma, may suggest the likelihood of facial canal dehiscence. This study was conducted to assess the relationship between ossicular chain erosion and facial canal dehiscence in chronic otitis media squamous.
\end{abstract}

\section{Methods}

It is a retrospective chart review of patients who had mastoidectomy done for chronic otitis media squamous in Tribhuvan University Teaching Hospital from January 2014 to December 2018. The operative findings of facial canal dehiscence were correlated with ossicular chain status.

\section{Results}

Among 158 cases, facial canal dehiscence was seen in 20 (12.7\%), of which, 19/20 (95\%) had ossicular erosion. Majority (90\%) of dehiscence was in the horizontal segment. Incus was the most common ossicle to be eroded. Among the ossicles, stapes erosion was related to the facial canal dehiscence with odds ratio of $3.216(1.235-8.374)$ and p-value 0.03 .

\section{Conclusion}

Among the ossicles, there is a relationship between the stapes erosion and the facial canal dehiscence in chronic otitis squamous. Erosion of ossicular chain especially stapes should alert surgeons towards the possibility of facial canal dehiscence.

Keywords: Chronic otitis media squamous, facial canal, ossicular erosion 


\section{INTRODUCTION}

C holesteatoma which is pathognomonic of chronic otitis media (COM) squamous type, is a pocket or cystic lesion lined by stratified squamous epithelium containing proliferative keratin. ${ }^{1}$ Cholesteatoma is a gradually expanding destructive lesion and leads to complications by eroding the adjacent structures. Erosion caused by bone resorption of the ossicular chain and otic capsule results in profound hearing loss, vestibular dysfunction, facial nerve paralysis, and intracranial complications. ${ }^{2}$ The bony erosion of ossicles and middle ear structures share the same multifactorial pathogenesis which is a combination of osteitis, pressure necrosis, and lysis mediated by enzymes and cytokines like tumor necrosis factor-alpha, interleukin-2, fibroblast growth factor, and plateletderived growth factor. 3,4

In mastoid surgery, facial canal dehiscence and erosion of ossicular chain are encountered. The incidence of facial canal dehiscence varies from $0.5 \%$ to $74 \%$, the tympanic segment near the oval window being the commonest site followed by segment at the level of geniculate ganglion.5 latrogenic facial nerve injury ranges from 0.6-3.6\% with the risk further increasing to $4-10 \%$ in revision cases. ${ }^{6}$ The facial nerve is vulnerable to damage during mastoid surgery in presence of dehiscence which could be secondary to cholesteatoma related bone erosion or anatomical variations. ${ }^{7}$ Erosion of ossicular chain usually involves multiple ossicles rather than a single ossicle, with incus being involved in $30 \%$, stapes in $15 \%$ and malleus in $10 \% .^{8,9}$

Since the facial canal and the ossicles are in close proximity in the middle ear space and they share the same pathogenesis of the bony erosion due to cholesteatoma, ossicular chain erosion found intraoperatively may suggest the likelihood of facial canal dehiscence. This study was therefore conducted to assess the relationship between ossicular chain status and facial canal dehiscence in chronic otitis media with cholesteatoma.

\section{METHODS}

This was a retrospective study involving the chart review of 158 patients who had undergone mastoid surgery either in elective or emergency list for COM squamous type in the Department of ENT-Head and Neck Surgery, Tribhuvan University Teaching Hospital over five years from January 2014 to December 2018. It included patients of all age groups and gender. Ethical approval was taken from the Institutional Review Committee of Institute of Medicine before commencing the study.

The age, gender, associated complications of COM squamous, primary or revision mastoid surgery, and the extent of surgery were noted. The status of the facial canal and the ossicular chain were also noted. Dehiscence of the facial canal or ossicular chain erosion if found, the specific site or the ossicle involved were taken note of. The ossicular chain erosion and facial canal dehiscence were identified by inspection and palpation under the microscope. Cases in which there was no specific information regarding the status of the facial nerve and ossicular status were excluded. High-resolution computed tomography of temporal bone was not done routinely and was limited to revision cases and cases with complication.

Data was analyzed using SPSS version 25 software. Chi-square test and Fischer exact test were done for categorical variables and adjusted odds ratio was calculated keeping the statistical significance of p-value at 0.05

\section{RESULTS}

Among 158 patients, 104 (65.8\%) were males and $54(34.2 \%)$ were females. The age ranged from 8 to 63 years. The median age group was 20-40 years with $72(45.6 \%)$ patients in this group. The facial canal was normal in $138(87.3 \%)$ cases and dehiscent in $20(12.7 \%)$ cases. The majority (90\%) of the dehiscence was found in the horizontal segment near the oval window. Among 158 patients, four patients had complications at the time of surgery, one each of mastoid fistula, facial palsy with lateral semicircular canal fistula, Bezold's abscess, and subdural abscess. Dehiscence was found in $50 \%(2 / 4)$ cases with complication (Table 1). There were three revision cases for recurrence of cholesteatoma post mastoid surgery done in childhood (Table 2). There was no statistical significance between the facial canal dehiscence in revision mastoidectomy.

Out of the 20 cases with facial canal dehiscence, 19 $(95 \%)$ cases had either of ossicles eroded whereas only $1(5 \%)$ case had an intact ossicular chain (Table

Table 1. Comparison of facial canal dehiscence with different complications $(n=158)$

\begin{tabular}{|c|c|c|}
\hline \multirow{2}{*}{ Complications } & \multicolumn{2}{|c|}{ Facial canal } \\
\hline & Normal & Dehiscent \\
\hline \multicolumn{3}{|l|}{ Cases with complication $(n=4)$} \\
\hline Mastoid fistula & 1 & 0 \\
\hline Bezolds abscess & 0 & 1 \\
\hline Facial palsy with lateral & & \\
\hline semicircular canal fistula & 0 & 1 \\
\hline Subdural abscess & 1 & 0 \\
\hline \multicolumn{3}{|l|}{$\begin{array}{l}\text { Cases without complication } \\
(n=154)\end{array}$} \\
\hline Total & 138 & 20 \\
\hline
\end{tabular}


Table 2. Comparison of facial canal dehiscence with type of modified radical mastoidectomy $(n=158)$

\begin{tabular}{rcccc}
\hline \multirow{2}{*}{ MRM type } & Total & \multicolumn{2}{c}{ Facial canal } & p-value \\
\cline { 3 - 5 } & & Normal & Dehiscent & \\
\hline Revision MRM & 3 & 2 & 1 & 0.83 \\
Primary MRM & 155 & 136 & 19 & \\
Total & 158 & 138 & 20 & \\
\hline
\end{tabular}

Table 3. Comparison of ossicular chain status with facial canal dehiscence $(n=158)$

\begin{tabular}{|c|c|c|c|c|}
\hline \multirow{2}{*}{$\begin{array}{l}\text { Ossicular } \\
\text { status }\end{array}$} & \multirow{2}{*}{ Total } & \multicolumn{2}{|c|}{ Facial canal } & \multirow[t]{2}{*}{$p$-value } \\
\hline & & Normal & Dehiscent & \\
\hline Intact & 8 & 7 & 1 & 1 \\
\hline Erosion & 150 & 131 & 19 & \\
\hline Total & 158 & 138 & 20 & \\
\hline
\end{tabular}

Table 4. Relationship of individual ossicular status and facial canal dehiscence $(n=158)$

\begin{tabular}{|c|c|c|c|c|c|c|}
\hline \multirow{2}{*}{ Ossicle } & \multirow{2}{*}{$\begin{array}{l}\text { Ossicular } \\
\text { status }\end{array}$} & \multirow{2}{*}{ Total } & \multicolumn{2}{|c|}{ Facial canal } & \multirow{2}{*}{$\mathrm{p}$-value } & \multirow{2}{*}{$\begin{array}{l}\text { Odds ratio } \\
(95 \% \mathrm{Cl})\end{array}$} \\
\hline & & & Normal & Dehiscent & & \\
\hline Malleus & $\begin{array}{l}\text { Intact } \\
\text { Eroded }\end{array}$ & $\begin{array}{l}112 \\
46\end{array}$ & $\begin{array}{l}97(61.4 \%) \\
41(25.9 \%)\end{array}$ & $\begin{array}{l}15(9.5 \%) \\
5(3.2 \%)\end{array}$ & 0.67 & $0.789(0.27-2.31)$ \\
\hline Incus & $\begin{array}{l}\text { Intact } \\
\text { Eroded }\end{array}$ & $\begin{array}{c}13 \\
145\end{array}$ & $\begin{array}{c}12(7.6 \%) \\
126(79.7 \%)\end{array}$ & $\begin{array}{l}1(0.6 \%) \\
19(12 \%)\end{array}$ & 0.57 & $1.81(0.22-14.72)$ \\
\hline Stapes & $\begin{array}{l}\text { Intact } \\
\text { Eroded }\end{array}$ & $\begin{array}{c}109 \\
49\end{array}$ & $\begin{array}{c}100(63.3 \%) \\
38(24.1 \%)\end{array}$ & $\begin{array}{c}9(5.7 \%) \\
11(7 \%)\end{array}$ & 0.03 & $3.22(1.23-8.37)$ \\
\hline
\end{tabular}

3). However, this was not statistically significant. Out of the 158 cases, malleus, incus, stapes erosion was found in 46, 145, 49 cases respectively (Table 4). The most common ossicular erosion found was incus $145 / 158(91.77 \%)$ followed by stapes erosion $49 / 158(31.01 \%)$ and the malleus erosion which was the least $46 / 158$ (29.11\%). The maximum group with facial canal dehiscence was in incus absent cases. Among the ossicles, the stapes had a significant p-value with the facial canal dehiscence (Table 4). The odds ratio was 3.22 (1.23-8.37).

Similarly, there was a higher prevalence of facial canal dehiscence in cases with both incus and stapes defect or all ossicles eroded (Table 5). Isolated incus alone had a lower prevalence of $10.96 \%$ compared to incus and stapes defect of $21.87 \%$. Similarly, the highest prevalence was seen when all the ossicles were eroded (22.22\%).

\section{DISCUSSION}

Facial canal dehiscence may be congenital due to lack of ossification of the bony canal or may arise from resorptive osteitis secondary to

Table 5. Relationship of different ossicular status and facial canal dehiscence $(n=158)$

\begin{tabular}{lcc}
\hline \multicolumn{1}{c}{ Ossicular status } & \multicolumn{2}{c}{ Facial canal dehiscence } \\
\cline { 2 - 3 } & Ratio & Percentage \\
\hline Ossicular chain intact & $1 / 8$ & $12.50 \%$ \\
Isolated incus defect & $8 / 73$ & $10.96 \%$ \\
Incus and stapes defect & $7 / 32$ & $21.87 \%$ \\
All ossicular defective & $4 / 18$ & $22.22 \%$ \\
\hline
\end{tabular}

cholesteatoma. ${ }^{10}$ The prevalence of facial canal dehiscence is wide, ranging from $0.5 \%$ to $74 \%$. Interestingly its dehiscence has been reported higher in histologic studies than in operative cases due to the destruction of the bony covering of the facial nerve during processing or preparation of specimen. ${ }^{11}$ In our study, the dehiscence was seen in $12.7 \%$ of cases. The variation ranges in different inflammatory and non-inflammatory diseases like COM squamous vs mucosal vs otosclerosis.

The majority of clinical studies regarding facial canal dehiscence are related to mastoid and middle ear disease where the chronic otitis media causes the inflammatory resorptive osteitis leading to microscopic or macroscopic dehiscence. This is in contrast to the otosclerosis where the incidence is very low at $2.8(0.5-11.4 \%)$ in the tympanic segment. ${ }^{12}$ The reason could be because of the lack of inflammatory mechanism in otosclerosis.

The pathophysiology of erosion of ossicle and middle ear structures including the facial canal is thought to be multifactorial resulting from the combination of osteitis, pressure necrosis and lysis mediated by enzymes and cytokines - tumor necrosis factor (TNF) alpha, interleukin-2, fibroblast growth factor, and platelet-derived growth factor. ${ }^{3,4}$

Malleus is the toughest ossicle for erosion compared to other ossicles. The ossicle affected most commonly was incus followed by stapes. This

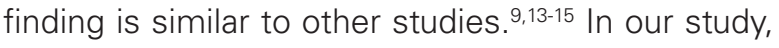
amongst the 20 cases with facial canal dehiscence, $19(95 \%)$ had ossicular chain erosion.

The exact prevalence of ossicular chain erosion in 
facial canal dehiscence in literature is lacking because of the heterogeneity of the studies available. Most studies compare the facial canal dehiscence and individual ossicular status. According to Sahin et al. facial canal dehiscence was lower in intact ossicular chain $8.7 \%$, with isolated incus erosion $3.1 \%$ compared to the erosion of suprastructure of stapes and incus $60.7 \%$, and with total erosion of ossicular chain $43.2 \% .{ }^{16}$ In our study, there is similar low incidence in the intact ossicular group (12.5\%) and isolated incus erosion group (10.96\%).

Some authors strongly support that stapes erosion is closely associated with the facial canal dehiscence. $6,10,17,18$ Our study also had a similar finding with erosion of stapes significantly associated to the facial canal dehiscence. In order to further analyze the finding, the regression analysis was done which supported our results with the adjusted odds ratio of 3.216 (1.235-8.374). Association of erosion of other ossicles were not statistically significant.

The erosion of facial canal and the ossicles share the same pathogenesis which explains the concurrent facial canal dehiscence and the ossicular chain erosion. In addition, incus is more at risk due to its thin blood vasculature. The close proximity of stapes with facial canal is considered a reason for stapes erosion to be associated facial canal dehiscence secondary to destructive effect of cholesteatoma. ${ }^{6}$

Some authors have however refuted this explanation and considered the possibility of pre-existing facial canal dehiscence in mastoid surgery. ${ }^{18}$ This too remains debatable as various histologic studies found facial canal dehiscence to be common but considered them artefactual occurring secondary to destruction of the bone covering the facial nerve during processing or preparation of specimen. ${ }^{11}$

The association between the stapes erosion and the facial canal dehiscence as seen in this study helps to increase the awareness amongst young surgeons about the likeliness of facial canal dehiscence to minimize the risk of facial nerve injury especially in revision cases, those with complications, and cases with extensive granulation in the middle ear.

The positive aspect of our study is that only very few revision cases have been included in contrast to other studies. In revision cases, there is a likeliness that the ossicles mainly malleus and often incus could already have been removed in the previous surgery which could be lead to error in interpretation of relationship of ossicular erosion with facial canal dehiscence.

One of the main limitations of the study is its retrospective study design. A prospective study with a large sample is needed for further analysis.

\section{CONCLUSION}

There is a relationship between the stapes erosion and the facial canal dehiscence. Hence, in a cholesteatoma case an eroded ossicular status especially stapes should alert surgeons towards the possibility of facial canal dehiscence to minimize the risk of inadvertent facial nerve injury.

\section{CONFLICT OF INTEREST}

None declared.

\section{REFERENCES}

1. Wang HM, Lin JC, Lee KW et al. Analysis of mastoid findings at surgery to treat middle ear cholesteatoma Arch Otolaryngol. 2006 Dec;132(12):1307-10.

2. Olszewska E, Wagner M, Bernal SM, et al. Etiopathogenesis of cholesteatoma. Eur. Arch. Oto-Rhino-L 2004 Jan;261(1):6-24.

3. Yetiser S, Satar B, Aydin N. Expression of epidermal growth factor, tumor necrosis factor- $\alpha$, and interleukin- $1 \alpha$ in chronic otitis media with or without cholesteatoma. Otol Neurotol. 2002 Sep;23(5):647-52.

4. Kurihara A, Yuasa R, Toshima M et al. Bone destruction mechanisms in chronic otitis media with cholesteatoma: specific production by cholesteatoma tissue in culture of bone-resorbing activity attributable to interleukin-1 alpha. Ann. Otol. Rhinol. Laryngol. 1991 Dec;100(12):989-98.

5. Li D, Cao Y. Facial canal dehiscence: a report of 1,465 stapes operations. Ann. Otol. Rhinol. Laryngol. 1996 Jun; 105(6):467-71.

6. Gülüstan F, Aslan H, Songu M et al. Relationships between facial canal dehiscence and other intraoperative findings in chronic otitis media with cholesteatoma. Am J Otolaryng. 2014;35(6):791-5.

7. Moreano EH, Paparella MM, Zelterman D et al. Prevalence of facial canal dehiscence and of persistent stapedial artery in the human middle ear: a report of 1000 temporal bones. Laryngoscope 1994 Mar;104(3):309-20.

8. Choi SA, Kang HM, Byun JY et al. Analysis of differences in facial nerve dehiscence and ossicular injury in chronic otitis media and cholesteatoma. Acta Otolaryngol 2014 May;134(5):455-461.

9. Akarcay M, Kalcioglu MT, Tuysuz 0 et al. Ossicular chain erosion in chronic otitis media patients with cholesteatoma or granulation tissue or without those: analysis of 915 cases. Eur Arch OtoRhino-L. 2019 May;276(5):1301-5.

10. Bulğurcu S, Arslan IBB, Dikilitaş B et al. Relation between ossicular erosion and destruction of facial and lateral semicircular canals in chronic otitis media. Int Arch Otorhinolaryngol. 2017 Sep;21(3):239-42.

11. Kim CW, Rho YS, Ahn HY et al. Facial canal dehiscence in the initial operation for chronic otitis media without cholesteatoma. Auris Nasus Larynx 2008 Sep;35(3):353-6.

12. Moody MW, Lambert PR. Incidence of dehiscence of the facial nerve in 416 cases of cholesteatoma. Otol Neurotol 2007;28(3):400-4.

13. Thakur S, Ghimire N, Acharya $R$ et al. Ossicular chain status in cholesteatoma. Asian J. Med. Sci.2017 May;8(3):68-71.

14. Albera R, Canale A, Piumetto $E$ et al. Ossicular chain lesions in cholesteatoma. Acta Otorhinolaryngol. 2012 Oct;32(5):309-13.

15. Varshney S, Nangia A, Bist SS et al. Ossicular chain status in chronic suppurative otitis media in adults. Indian J Otolaryngol Head Neck Surg 2010 Oct; 62(4):421-26.

16. Sahin MM, Cayonu M, Dinc AS et al. Cautionary Findings for the Presence of Facial Canal Dehiscence During Cholesteatoma Surgery Ear Nose Throat J.2019 Jun;98(5):253-54.

17. Chan KC, Wang PC, Chen YA et al. Facial nerve dehiscence at mastoidectomy for cholesteatoma. J Int Adv Otol. 2011 Oct;7(3):311-16.

18. Rijal AS, Joshi RR, Dhungana A et al. Facial canal Dehiscence in Modified Radical Mastoidectomy and Facial Nerve Status. Nepal Med Coll J. 2016;18(1-2):40-43. 